\title{
Function and misfunction of the two promoters of the Drosophila Antennapedia gene
}

\author{
Erik M. Jorgensen and Richard L. Garber
}

Department of Genetics, SK-50, University of Washington, Seattle, Washington 98195 USA

In the Antennapedia (Antp) gene of Drosophila melanogaster, structurally distinct RNAs arise from different transcription initiation sites. When the two sites are separated by a chromosome inversion, transcripts are produced from each fragment of the split Antp locus, and these RNAs initiate at the same nucleotide as in wild-type animals. Thus, the initiation sites are regulated by independent promoters. We show by in situ hybridization that transcripts from each promoter accumulate in spatially distinct patterns in a subset of wildtype imaginal discs. Importantly, these patterns are generally maintained in the inversion mutant. We conclude that the promoters possess independent and dissimilar regulatory elements for spatial activation. Finally, we have looked at transcription in seven different dominant Antp mutants, all of which show a transformation of head tissue to thoracic tissue. In each mutant, the second promoter is improperly activated in the eye-antennal imaginal disc. Because all but one of these mutations have inversion breakpoints distantly upstream of the activated promoter, they probably act via long-range euchromatic position effects. Our studies define how the dual promoters and chromatin structure of the Antp gene contribute to the generation of a complex pattern of transcription.

[Key Words: Antennapedia; two promoters; cell-specific expression; in situ hybridization; homeotic gene; long-range chromatin effects]

Received April 27, 1987; accepted June 10, 1987.

The Antennapedia (Antp) gene is necessary for the proper development of thoracic segments in both larval and adult stages of Drosophila. Animals lacking the Antp locus die as embryos (Denell et al. 1981), and the cuticle of the three thoracic segments (the pro-, meso-, and metathorax) is partially transformed to cuticle of more anterior segments (Wakimoto and Kaufman 1981; Sato et al. 1985; Martinez-Arias 1986). Antp also functions in the imaginal discs (the developing adult cells) to repress head development and to promote thoracic development (Struhl 1981; Schneuwly and Gehring 1985; Abbott and Kaufman 1986). Consistent with this thorax-determining role, dominant mutations of Antp cause striking homeotic transformations of head structures into thoracic structures (typically, antennae are transformed into legs). Because the Antp gene is not needed for normal head development (Denell et al. 1981; Struhl 1981), the dominant transformation appears to result from the expression of the thorax-specifying functions of Antp in the wrong tissue.

The Antp gene is unusually large; its eight exons span over 100 kilobase pairs $(\mathrm{kb})$ of genomic DNA (Garber et al. 1983; Scott et al. 1983; Laughon et al. 1986; Schneuwly et al. 1986). The open reading frame is contained in four major transcript types, which are gener- ated by alternative choices at two steps in RNA synthesis: initiation and 3 ' processing (Fig. 1). Transcripts begin at alternative exons, which leads to different $5^{\prime}$ sequences preceding the open reading frame; and transcripts end at alternative polyadenylation sites, which leads to two types of 3' untranslated sequences. Because the transcription initiation sites at exon 1 and exon 3 are separated by $70 \mathrm{~kb}$, it has been proposed that these RNAs originate from different promoters (Laughon et al. 1986; Schneuwly et al. 1986; Stroeher et al. 1986). In this paper we present functional proof that the two start sites represent independent promoters. We would like to answer the question, Why are there two promoters?

The functional significance of multiple promoters has been demonstrated for other genes. For example, slightly different proteins are produced by alternative $5^{\prime}$ exons in the yeast invertase gene (Carlson and Botstein 1982; Perlman et al. 1982). In contrast, two promoters sometimes direct the synthesis of the same protein, but the promoters are active at different times in development. Such developmental specificity is directed by the two promoters in the alcohol dehydrogenase gene of Drosophila melanogaster (Benyajati et al. 1983). Finally, multiple promoters can direct transcription in different tissues. For example, different promoters transcribe the 


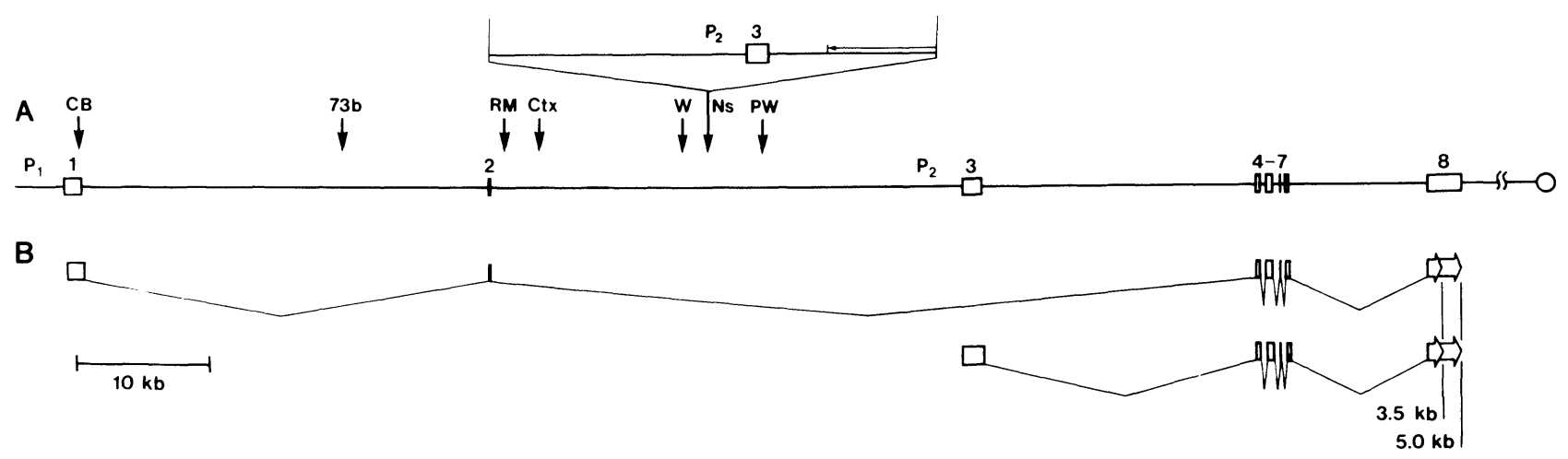

Figure 1. Scale drawing of the Antp locus. (A) Genomic DNA map of the 100-kb locus. Numbered boxes refer to the exons; the open circle designates the centromere; the arrows above the map refer to the breakpoints of the inversion mutations (Garber et al. 1983; Scott et al. 1983; Abbott and Kaufman 1986). Ant $p^{N s}$ is a 25-kb duplication of the exon 3 region, with a roo transposon separating the duplicated sequences (P. Talbert, unpubl.). Arrows indicate orientation of the element. $(B)$ Structure of the major transcripts from the gene. Transcription can initiate at either exon 1 (P1) or exon $3(\mathrm{P} 2)$. Transcripts originating from either site are processed at one of two polyadenylation sites in exon 8 , yielding RNAs 5.0 or $3.5 \mathrm{~kb}$ in size. The open reading frame is contained in exons $5-8$.

murine $\alpha$-amylase gene in the liver and the parotid gland (Schibler et al. 1983). Previous investigations of the Antp gene did not reveal any of the above functional distinctions between the initiation sites. First, the alternative $5^{\prime}$ exons do not contain any portion of the open reading frame; therefore, they cannot encode proteins with different 5' domains (Laughon et al. 1986; Schneuwly et al. 1986; Stroeher et al. 1986). Although alternative splicing does produce short sequence differences within the open reading frame, no association with a particular promoter has been observed (V. Stroeher, C. Gaiser, and R. Garber, in prep.). Second, both RNA initiation sites are used at the embryonic, larval, pupal, and adult stages of development (Schneuwly et al. 1986; E. Jorgensen, unpubl.). Finally, analysis of imaginal disc RNA revealed no gross tissue specificity for either start site (Stroeher et al. 1986).

In contrast to the RNA blot results, we demonstrate by in situ hybridization that the two promoters do, in fact, direct spatially distinct RNA accumulation within mesothoracic imaginal discs. This result indicates that one function of the two Antp promoters is to achieve a complex cell-specific pattern of gene expression. These different patterns of RNA accumulation are mostly undisturbed by an inversion mutation, again underscoring the independence of the two promoters. Finally, dominant mutations of Antp activate the second promoter ectopically in the eye-antennal discs, even though the inversion breakpoints are very distant from the start of transcription.

\section{Results}

\section{The Antp gene utilizes two independent promoters}

Though the mapping of the transcription initiation sites provides strong evidence that Antp is controlled by two promoters, proof requires us to demonstrate that each isolated site can function alone as a promoter.

The Antennapedia of Wu $\left(A n t p^{W}\right)$ mutation (Scott et al. 1983) is a chromosome inversion which breaks the
Antp gene $20 \mathrm{~kb}$ upstream of the second transcription start site, thereby separating the initiation sites (Fig. 1). The mutation leads to both dominant and recessive phenotypes. In heterozygous $\left(A n t p^{W} /+\mid\right.$ adults the antennae are transformed into second thoracic legs. Homozygous $\left(A n t p^{W} / A n t p^{W}\right)$ animals, referred to as $A n t p^{W}$ larvae, die during postlarval development. This late lethal period allowed us to extract RNA from tissues of homozygous third instar larvae. We hypothesized that if the Antp locus contains two independent promoters, initiation of transcription at either of the RNA start sites reported previously should not be disrupted by the mutation.

RNA initiation sites are located at the $5^{\prime}$ ends of exon 1 and exon 3 (see Fig. 1; Laughon et al. 1986; Schneuwly et al. 1986; Stroeher et al. 1986). RNase protection was used to assay transcription initiation in $A n t p^{W}$ and wildtype larvae. When we used probes including the $5^{\prime}$ ends of exon 1 or exon 3 , fragments of identical sizes were protected in the two genotypes (Fig. 2). Although the rearrangement positions the start sites on different arms of the third chromosome, transcripts are still produced from each fragment of the locus, and these RNAs initiate at the correct nucleotides. These results demonstrate that independent promoters direct RNA synthesis at exon 1 (promoter 1) and at exon 3 (promoter 2).

Transcripts from the different Antp promoters accumulate in different cells in the mesothoracic imaginal discs

RNA blots of wild-type larval tissues have previously shown that Antp transcripts accumulate in all the thoracic imaginal discs, the brain, and the ventral nerve cord (Stroeher et al. 1986). No tissue specificity was found for the two RNA classes. To examine this question in more detail, we have now performed in situ hybridization to wild-type imaginal discs using probes homologous to exon 1 [unique to promoter 1 (P1) transcripts] or exon 3 [unique to promoter 2 (P2) transcripts]. 


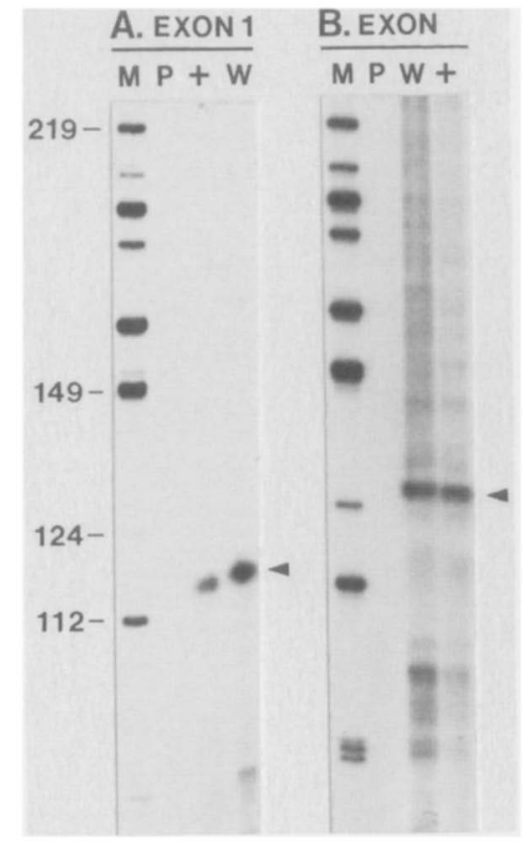

Figure 2. Transcription initiation is normal in $A n t p^{W}$ larvae. ${ }^{32} \mathrm{P}$-labeled antisense RNA probes were annealed to total RNA from wild-type third instar larvae (+), total RNA from Antpw/ $A n t p^{W}$ third instar larvae (W), or no RNA (P). The annealed RNA was digested with RNase $A$ and RNase $T_{1}$ to remove single-stranded regions. The protected fragments were denatured, fractionated on a polyacrylamide gel along with ${ }^{32} \mathrm{P}$-labeled DNA markers ( $M$; sizes indicated in basepairs), and autoradiographed. $(A)$ The probe includes the $5^{\prime}$ end of exon 1 , and the protected fragments are 115 bp long (arrowhead) when using $A n t p^{W} / A n t p^{W}$ or wild-type RNA. (B) The probe includes the 5' end of exon 3, and the protected fragments are 126 bp long (arrowhead), using $A n t p^{w} / A n t p^{w}$ or wild-type RNA.

We have discovered that RNAs from the different promoters accumulate in different cells within a tissue.

P1 transcripts accumulate primarily along the anterior margin of the wing disc (Fig. 3). This type of pattern was reported previously (Levine et al. 1983), but their probe did not distinguish between transcripts from the different promoters. Our results show that the P1 RNAs accumulate in high concentrations in the columnar epithelial cells along the anterior margin, in the cells of the anterior peripodial membrane, and in the tracheal cells. Additionally, the low levels of hybridization in the posterior portions of the disc are above background levels. Exon 1 hybridization is not coincident with the anterior-posterior compartment boundary, except perhaps at the mesopleural-pteropleural boundary on the ventral edge of the disc. The term "compartment" is used to define groups of cells whose progeny have a restricted developmental fate (Brower et al. 1981). From disc fate maps, the epithelial cells that express P1 RNAs strongly will develop into anterior structures of the adult segment: the prescutum, mesopleura, and pteropleura (Bryant 1975; Milner et al. 1984; see Fig. 5). It is important to note that the distribution of P1 RNA in the anterior epithelial cells of the wing disc is coincident with the cells affected by Antp mutations (Schneuwly and Gehring 1985; Abbott and Kaufman 1986).

P1 transcripts also accumulate along the anterior margin of the mesothoracic leg disc. Frontal (Fig. 3A) and transverse sections (data not shown) indicate that the transcripts are located in the columnar epithelial cells of the disc, which will differentiate into portions of the sternopleura and coxa of the adult leg (Milner et al. 1984; G. Schubiger, pers. comm.). Again, the hybridization pattern does not correspond to the compartment boundary (Steiner 1976; G. Schubiger, pers. comm.). The biological relevance of P1 transcripts in the leg discs is unclear, as their absence in Antp mutants produces no mutant phenotype (Schneuwly and Gehring 1985; Abbott and Kaufman 1986).

In contrast to the pattern of RNAs controlled by P1, P2 transcripts accumulate more evenly across the wing disc (Fig. 4A-C). The greatest hybridization of exon 3 probes is in the tracheal cells, in a band of cells just dorsal to the wing pouch, and in the adepithelial cells attached to the presumptive notum (for nomenclature, see Fig. 5). The adepithelial cells will contribute to the formation of the mesothoracic musculature (reviewed by Poodry 1980). Oddly, mitotic recombination experiments (Abbott and Kaufman 1986) revealed no function for Antp in regions of the wing disc unique to P2 transcripts (e.g., the dorsal wing hinge). It is possible that the observed transcriptional activity of $\mathrm{P} 2$ in the wing disc epithelium has no biological function. P2 transcripts are also fairly evenly distributed in the mesothoracic leg disc (Fig. 4D). There, appropriately, clones homozygous for Antp mutations transform the proximal portions of the mesothoracic leg to antenna (Struhl 1981) or cause fusion of leg segments (Abbott and Kaufman 1986).

Transcripts from P1 and P2 are present in the prothoracic and metathoracic leg discs, but no distribution differences between the promoters was noted (data not shown). Transcripts from both promoters accumulated fairly evenly across the discs, with slightly greater concentrations in cells destined to form proximal leg structures (Schubiger 1968). No transcripts were detected in the eye-antennal discs, and hybridization signals for the haltere disc were too low to be analyzed accurately.

From the analysis described above, we conclude that the two Antp promoters direct spatially distinct transcript accumulation. We do not know whether differential mRNA localization is caused by cell-specific transcription from each promoter or by cell-specific differences in RNA stability. If RNA stability plays a role, it must be mediated by the different $5^{\prime}$ ends because these RNAs are identical for the rest of their lengths.

\section{The thoracic distribution of Antp transcripts is mostly unaltered by the Antp ${ }^{\mathrm{W}}$ inversion}

We next asked whether the $A n t p^{W}$ inversion disrupts the proper spatial activation of either Antp promoter. RNA blot analysis and in situ hybridization were used to study RNA distribution in $A n t p^{W}$ imaginal discs.

Exon 1 (the P1-specific probe) hybridizes to 3.5 - and 5.0-kb transcripts in wild-type RNA (Scott et al. 1983). 


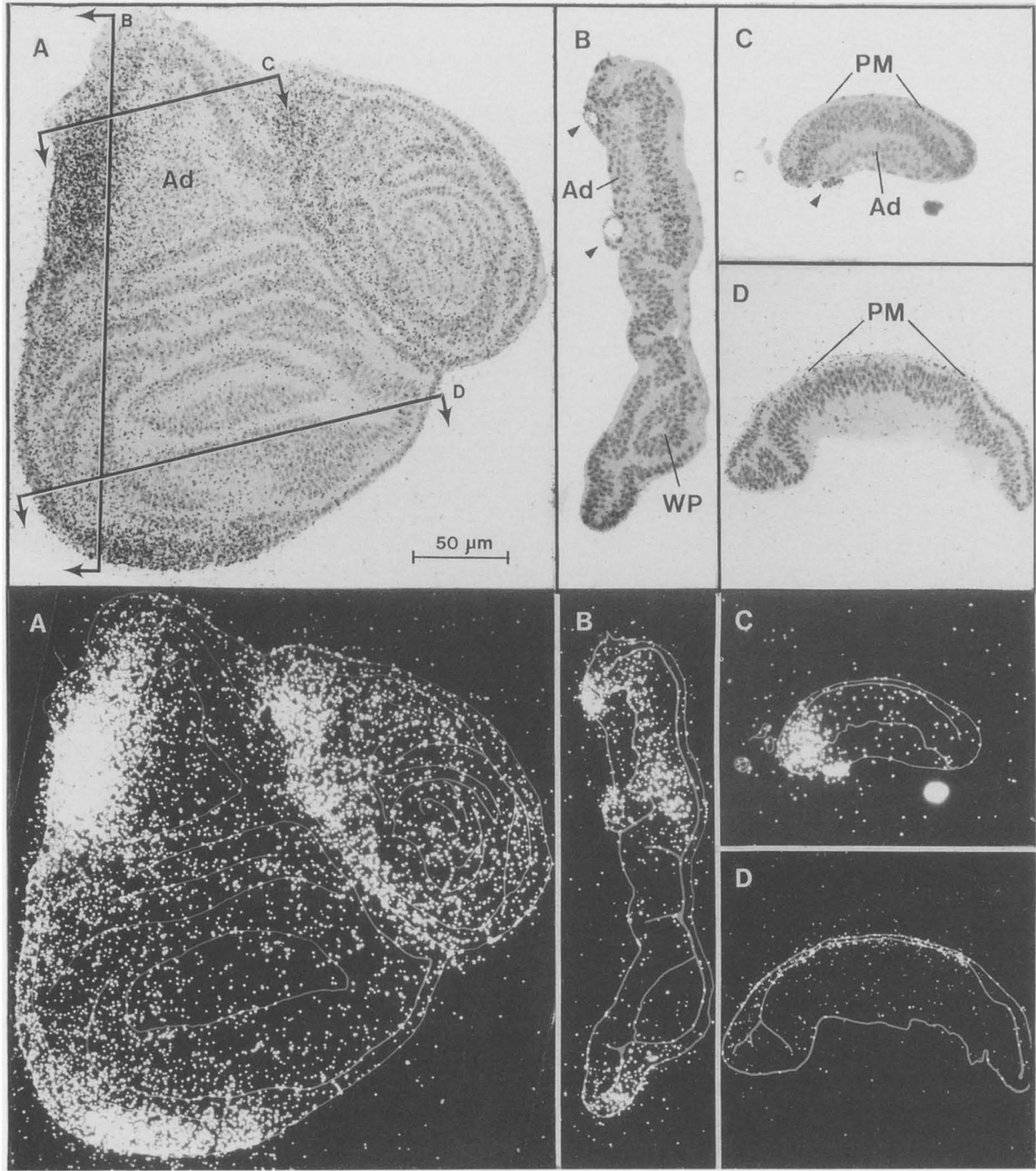

Figure 3. Location of P1 transcripts. Wild-type imaginal discs were hybridized in situ with a ${ }^{35}$ S-labeled probe specific for P1 (exon 1 ), sectioned, and covered with photosensitive emulsion. Tissue was counterstained with Giemsa and photographed in bright field for the upper panel. The same sections were photographed below under dark field to show silver grains; gray outlines have been added to show cell boundaries. Adepithelial cells (Ad), peripodial membrane (PM), and trachea (arrowheads) are indicated. $(A \mid$ Frontal section of a wing disc and an attached mesothoracic leg disc; anterior is to the left. The orientations of sections $B-D$ are shown by lines with arrows. Exposure time is 10 days. $(B)$ Sagittal section of a wing disc. $(C)$ Transverse section through the presumptive notum of a wing disc. (D) Transverse section through the wing pouch (WP) of a wing disc.

On blots of $A n t p^{W}$ RNA, the exon 1 probe detected transcripts of novel sizes (Fig. 6A). Most likely, the altered sizes reflect transcripts initiated at $\mathrm{P} 1$ and terminated in the non-Antp DNA juxtaposed by the chromosome rearrangement. P1 transcripts in $A n t p^{W}$ homozygotes accumulate in leg and wing imaginal discs and in the ventral nerve cord as in wild-type larvae (Stroeher et al. 1986). In brain tissue, however, these transcripts are reduced about 20-fold from the normal level.

When an exon 3 probe (specific for P2 RNAs) was hybridized to RNA blots of $A n t p^{W}$ dissected tissue, only wild-type-sized transcripts were detected (Fig. 6B). Exon 

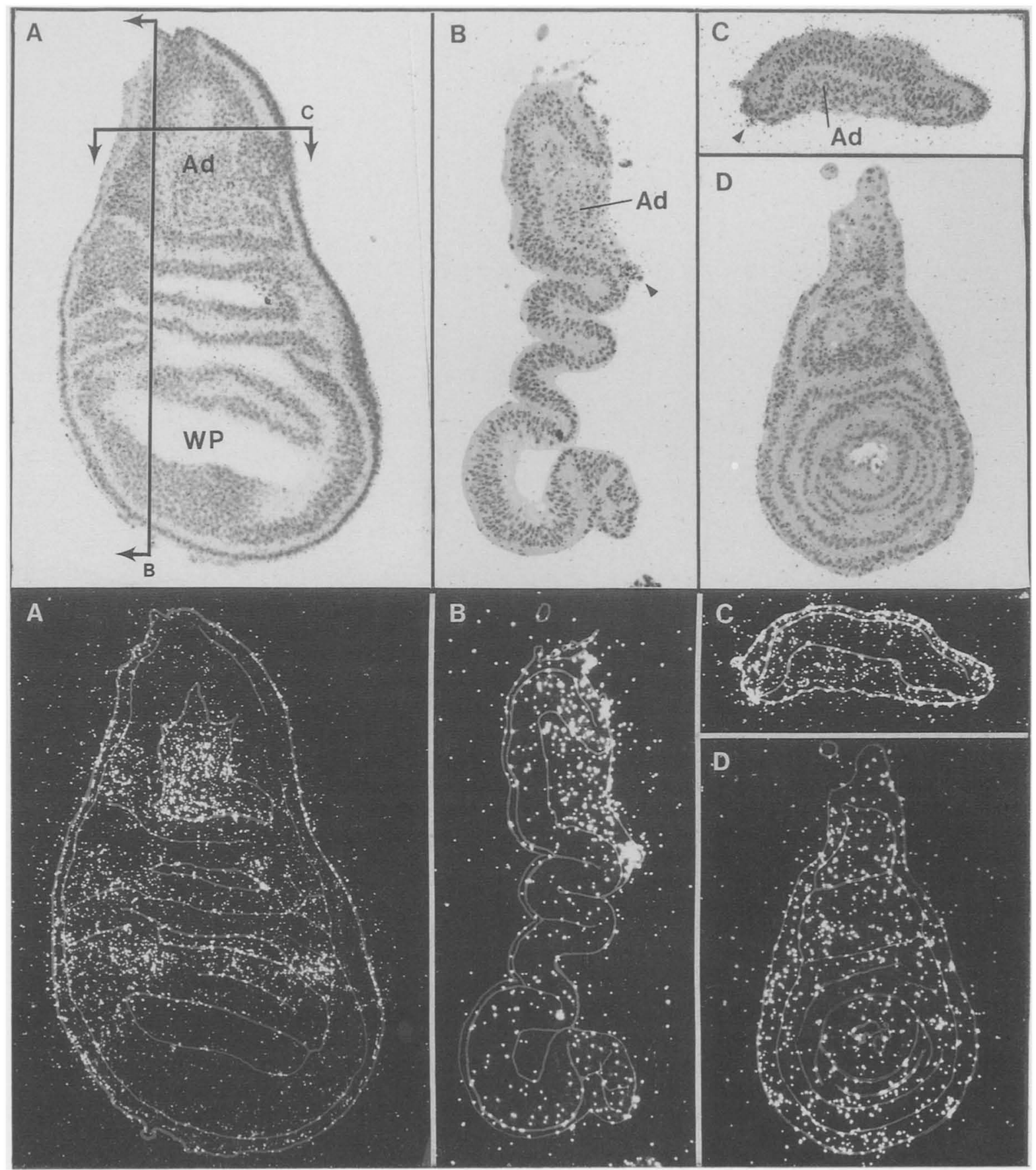

Figure 4. Location of $\mathrm{P} 2$ transcripts. Wild-type imaginal discs were hybridized with probes specific for P2 (exon 3), sectioned, and dipped in photosensitive emulsion. Bright- and dark-field photographs and symbols are described in the legend to Fig. 3. (A) Frontal section of a wing disc; anterior is to the left. The orientations of sections $B$ and $C$ are shown by lines with arrows. Exposure time is 20 days. $(B)$ Sagittal section of wing disc. $(C)$ Transverse section across the presumptive notum of a wing disc. $(D)$ Frontal section of a mesothoracic leg disc.

8 probes hybridize to 5.0 - and $3.5-\mathrm{kb}$ bands as well, which is consistent with these RNAs being normal P2 transcripts (Fig. 6C). As in wild-type third instar larvae (Stroeher et al. 1986), P2 transcripts were detected in the brain, the ventral nerve cord, and leg and wing imaginal discs of $A n t p^{W}$ larvae. The predominance of the $5.0-\mathrm{kb}$ transcript seen in the nervous tissue is also observed in wild-type larvae. The most striking difference between the two genotypes is the presence of P2 RNAs in Antpw eye-antennal discs, whereas, no Antp messages are detected in wild-type eye-antennal discs. Thus, the inversion has little or no influence on Antp expression in thoracic cells; it has a remarkable effect on head cells. This ectopic activity of the Antp gene is the apparent cause of 
A

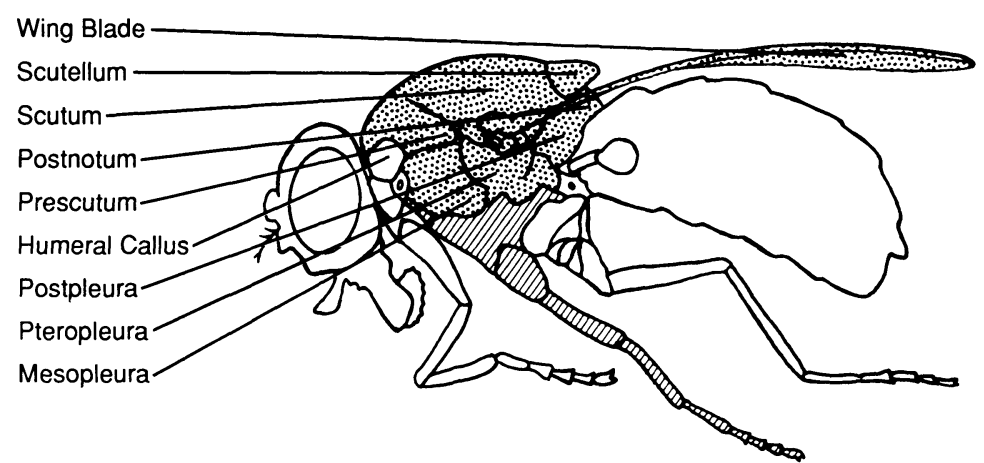

B

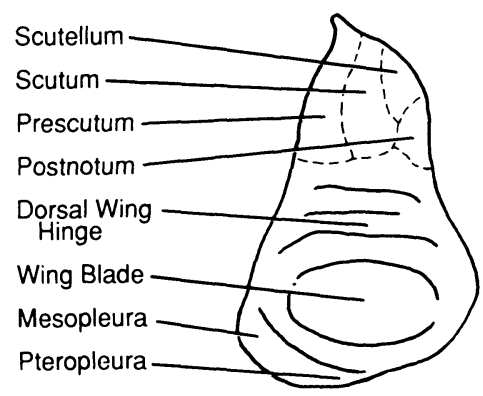

Figure 5. Adult morphology and wing imaginal disc fate map. (A) Adult derivatives of the wing (stippled) and mesothoracic leg (hatched) imaginal discs. The notum consists of the prescutum, scutum, scutellum, and postnotum. $(B)$ Wing disc fate map, adapted from Bryant (1975). The postpleura and portions of mesopleura, pteropleura, and postnotum are derived from the peripodial membrane (Milner et al. 1984).

the antenna-to-leg transformation seen in the heterozygous Antp ${ }^{w}$ adults, and it will be discussed more fully below.

At the detailed level of in situ hybridization to whole wing imaginal discs, the unique distribution of transcripts is generally maintained in $A n t p^{W}$ larvae (Fig. 7). P1 transcripts accumulate along the anterior margin of the wing disc, as in wild-type animals. However, long exposures show that P1 RNAs also accumulate in two new spots in the posterior half of the wing disc. The Antp open reading frame is not contained in these RNAs; hence, the functional protein would not be produced in these cells. What activates P1 in these cells? One hypothesis is that the inversion removes a repressor element necessary to keep transcription off in these cells. Because the breakpoints of $A n t p^{W}$ and another allele, $A n t p^{P W}$, are near one another, the presumed repressor element may be deleted in both cases. However, these spots did not appear in $A n t p^{P W} /+$ wing discs when in situ hybridized with exon 1 (data not shown). Thus, it is likely that the abnormal activation is an effect of the DNA brought adjacent to P1 by the inversion. P2 transcripts accumulate fairly evenly across the mutant discs, as they do in wild type. Because both Antp promoters are, for the most part, active in their normal regions, even when separated by an inversion, the promoters probably share no elements required for either transcription initiation or spatial activation in the imaginal discs.

In summary, the distributions of P1 and P2 mRNAs are maintained, with the exception of the three cited cases. We conclude that for the most part, each fragment of the Antp locus possesses the elements necessary for proper activation, and the cis-relationship between these promoters is not essential.

\section{Dominant mutations activate P2 in eye-antennal discs}

Most dominant mutations of Antp are chromosomal inversions that break the locus between exons 1 and 3 /Fig. 1). Such mutations may misregulate Antp by producing fusion RNAs with the $5^{\prime}$ end from a juxtaposed gene and the $3^{\prime}$ end from Antp. In short, the Antp open reading

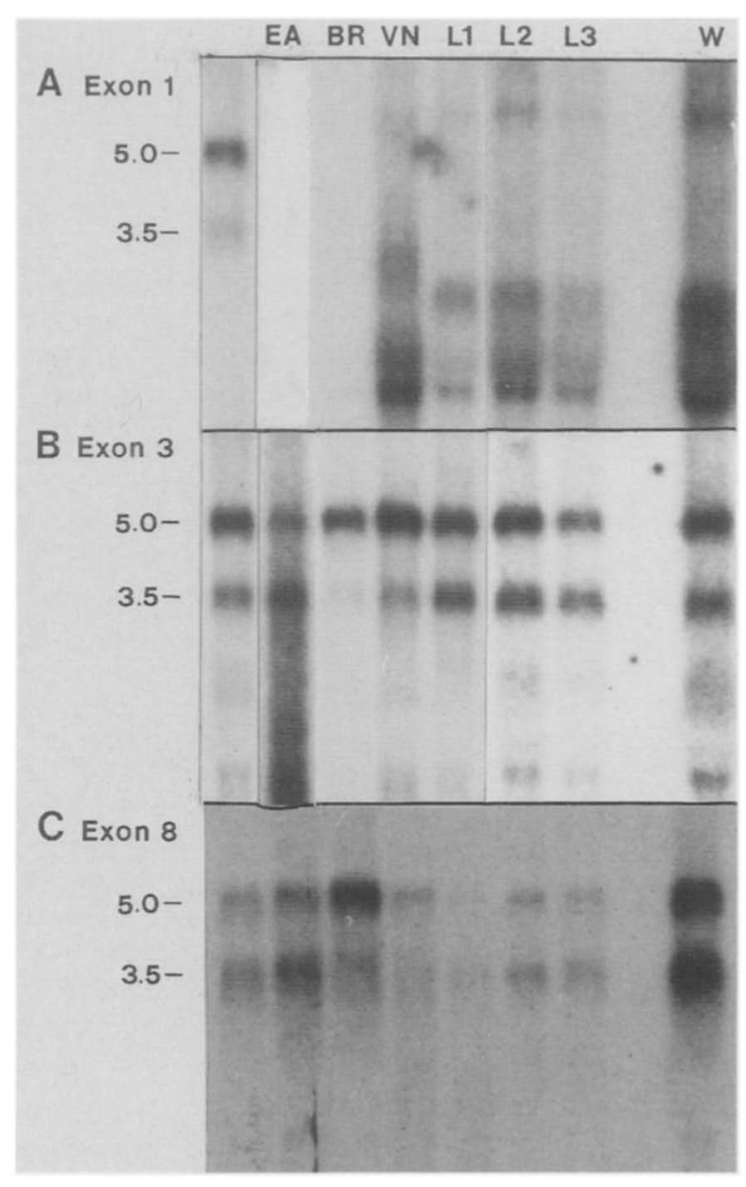

Figure 6. RNA distribution in $A n t p^{w}$ larval tissues. Total RNA was extracted from hand-dissected discs, fractionated on formaldehyde gels, blotted, and probed with exon $1(A)$, exon 3 $(B)$, or exon $8(C)$. The negative eye-antennal and brain lanes in $A$ showed 5.0- and 3.5-kb bands when rehybridized with exon 3 or exon 8 probes (data not shown). (EM) Marker lane of total RNA from wild-type embryos; (EA) eye-antennal discs; (BR) brain lobes; (VN) ventral nerve cords; (L1) prothoracic leg discs; (L2) mesothoracic leg discs; (L3) metathoracic leg discs; (W) wing discs. 


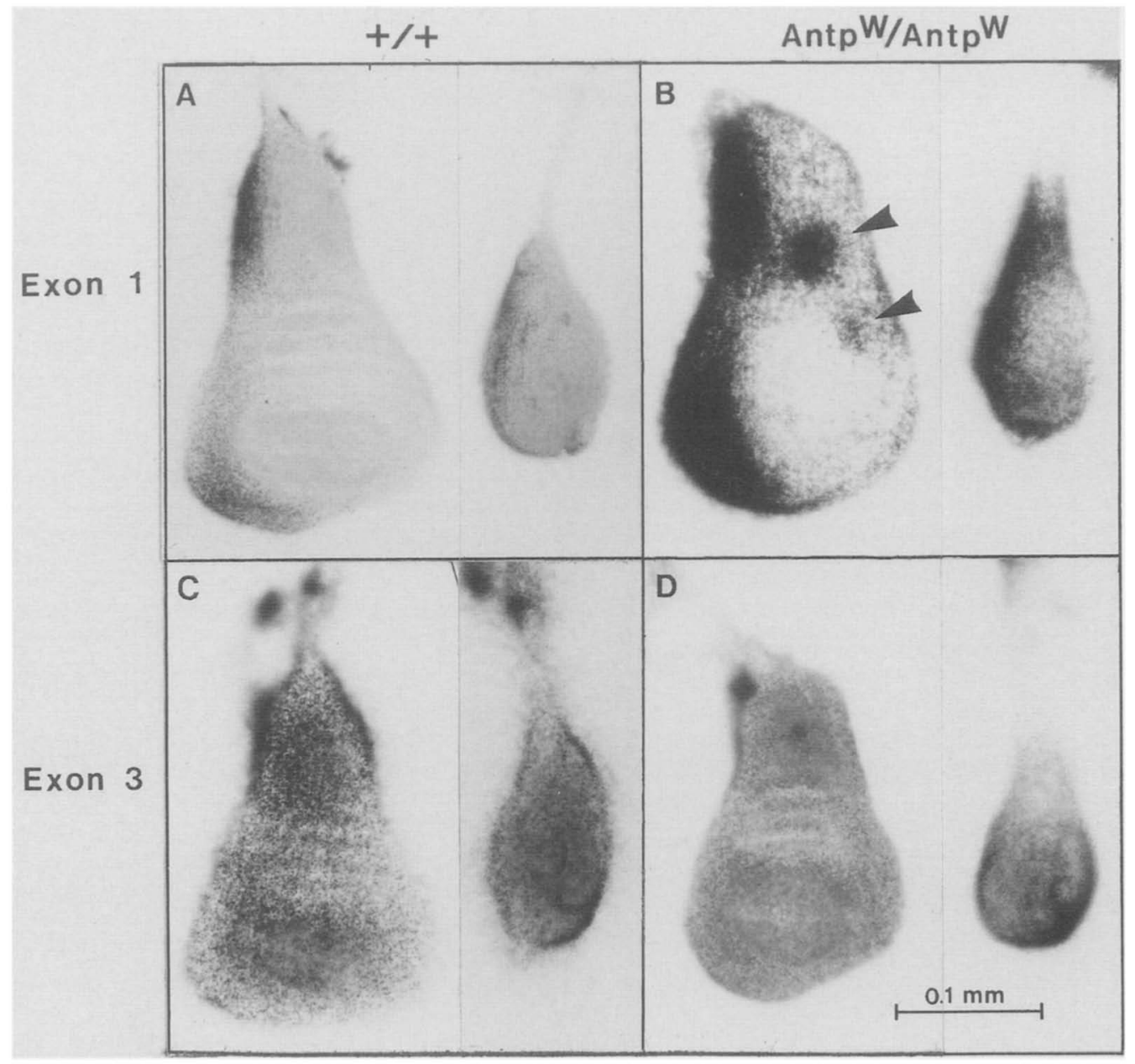

Figure 7. RNA location within wild-type and $A n t p^{w}$ whole mesothoracic imaginal discs. Exon 1 was hybridized to wing and mesothoracic leg discs from wild-type $(A)$ and $A n t p^{w} / A n t p^{w}(B)$ animals. Exon 1 transcripts accumulate in two additional positions (arrowheads) of $A n t p^{W} / A n t p^{w}$ wing discs. Exon 3 was also hybridized to wild-type $(C)$ and $A n t p^{W} / A n t p^{W}(D)$ wing and mesothoracic leg discs. Anterior is to the left.

frame would be under the tissue specificity of a foreign promoter. Analysis of the dominant mutant, Antp ${ }^{73 b}$, confirmed this model. Fusion transcripts initiate in a gene brought adjacent by the inversion and continue into the open reading frame of the Antp gene (Frischer et al. 1986; Schneuwly et al. 1987b). No fusion transcripts were detected in $A n t p^{W}$ tissues when hybridized with an open reading frame probe from exon 8 (Fig. $6 \mathrm{C}$ ); only P2 transcripts were detected in the eye-antennal discs. In $A n t p^{73 b} /+$ eye-antennal discs, normal P2, as well as fusion transcripts were detected (Frischer et al. 1986). The presence of P2 transcripts in both $A n t p^{73 b}$ and Antp ${ }^{W}$ eye-antennal discs led us to investigate the mechanism of ectopic activation of Antp in other dominant mutants. RNAs from the eye-antennal discs of five other mutants were gel-fractionated, blotted, and hybridized with Antp probes (Fig. 8). Each mutant accumulates P2 transcripts in eye-antennal imaginal discs. Ant $p^{C B}$ additionally produces novel-size exon 8-containing transcripts, slightly larger than 5.0 and $3.5 \mathrm{~kb}$, which may make the mutation analogous to the gene fusion ob- served in $A n t p^{73 b}$. A novel $2.8-\mathrm{kb}$ exon 1-containing transcript accumulates in Antp $p^{R M} /+$ eye-antennal discs, and long exposures reveal exon 1-containing transcripts in $A n t p^{C t x} /+$ and $A n t p^{N s} / A n t p^{N s}$ eye-antennal discs. The P1 transcripts observed in $A n t p^{R M}$ and $A n t p^{C t x}$ probably have no effect on the phenotype because the inversions have disrupted their association with the open reading frame. In $A n t p^{N s} / A n t p^{N s}$ eye-antennal discs, P1 transcripts appear to be normal and could contribute to the phenotype.

Does the distribution of Antp transcripts coincide with the phenotypic transformation in these dominant mutants? In situ hybridization of Antp probes to $A n t p^{N s} / A n t p^{N s}$ and $A n t p^{W} / A n t p^{W}$ eye-antennal discs revealed that transcripts are localized primarily to the antennal disc, that is, to cells that are transformed in the adult (Fig. 9). The exact distribution of transcripts in the antennal discs differs between these two mutants: Antp transcripts are found throughout Antp ${ }^{W} / A n t p^{W}$ antennal discs and occasionally in portions of the eye disc, whereas in $A n t p^{N s} / A n t p^{N s}$ antennal discs, transcripts are 
usually confined to the anterior compartment (Morata and Lawrence 1978; Brower 1986) of the antennal disc and are occasionally found in portions of the eye disc. In Antp ${ }^{C t x}$, the eyes and head capsule are transformed to wing and mesonotum, but the antennae are usually intact (Duncan and Lewis 1982). In Antp ${ }^{C t x} /+$ eye-antennal discs, Antp transcripts are appropriately concentrated in the medial portion of the eye disc. However, transcript locations and phenotypic expression vary within a mutant, which makes an exact correlation between transcript location and phenotype difficult. For example, transcripts are often confined to the antennal portion of the $A n t p^{W}$ and $A n t p^{N s}$ discs and not observed in the eye regions; the degree of transformation in the adult also varies greatly between flies of the same genotype. Nevertheless, the overall correspondence between the in situ hybridization data and the phenotype of a particular mutant allows us to conclude that transcript location in the mutant eye-antennal discs coincides roughly with the transformed adult tissues.

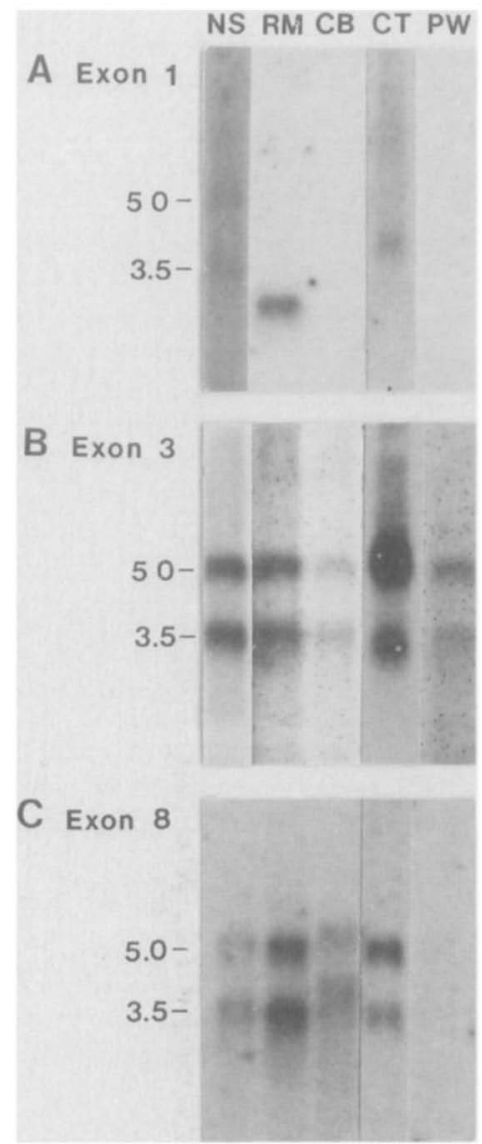

Figure 8. Blot analysis of eye-antennal disc RNA from Antp dominant mutants. Total RNA from the eye-antennal discs of $A n t p^{N s} / A t p^{N s}(\mathrm{NS}), A n t p^{R M} /+(\mathrm{RM}), A n t p^{C B /}+(\mathrm{CB}), A n t p^{C t x} /$ $+(\mathrm{CT})$, and $A n t p^{P \mathrm{~W}} /+(\mathrm{PW})$ third instar larvae was fractionated on formaldehyde gels, blotted, and probed with exon $1(A)$, exon $3(B)$, and exon $8(C)$. Negative lanes in $A$ showed 5.0- and 3.5$\mathrm{kb}$ bands when rehybridized with exon 3 probes. Exposure times are not identical.

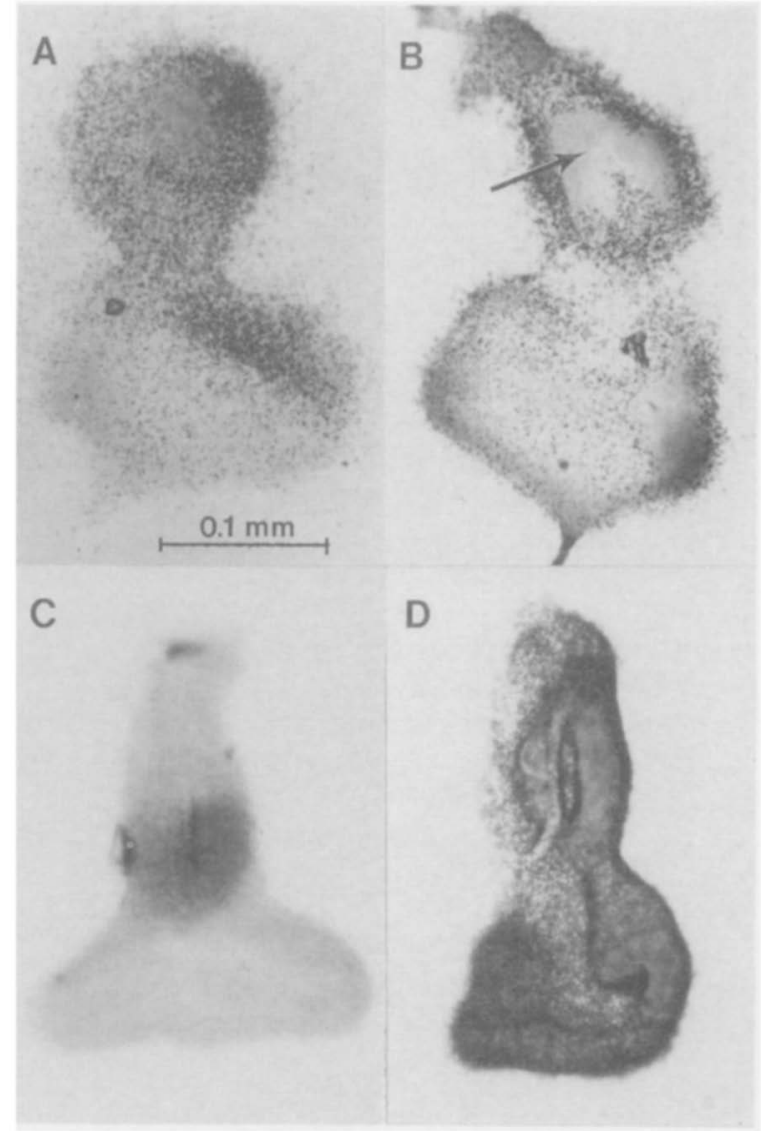

Figure 9. In situ hybridization to mutant eye-antennal discs. ${ }^{35} \mathrm{~S}$-Labeled probes specific for $\mathrm{P} 2$ transcripts were hybridized to whole eye-antennal discs from $A n t p^{W} / A n t p^{W}|A|, A n t p^{73 b} /+$ $(B), A n t p^{N s} / A n t p^{N s}(C)$, and $A n t p^{C t x} /+(D)$ larvae. The antennal portion of the disc is at the top, and the columnar cell side of the disc is visible. Hybridization in the $A n t p^{73 b} /+$ eye disc is above background when compared with wild-type controls. It is not known whether the background levels in $A n t p^{W} / A n t p^{W}$ and $A n t p^{C x} /+$ are significant. Because the $A n t p^{73 b} /+$ disc protrudes above the emulsion layer, silver grains are not in the center of the antennal disc (arrow). Rotated or flattened discs showed hybridization in this region as well.

Though Antp transcripts are found throughout the Ant $p^{w}$ antennal portion of the disc, only the most distal portions of the antennae are transformed in the adults. Moreover, transcripts are found throughout the eye and antennal portions of the Antp $p^{73 b} /+$ disc, but normally only portions derived from the antennal cells are transformed (Fig. 9; L. Frischer, unpubl.). In conclusion, the presence of Antp transcripts in the eye-antennal imaginal disc can lead to, but does not necessitate, cuticle transformations in the adult. Transformation may depend on other factors such as transcript abundance, the timing of expression, as well as the sensitivity of the target tissue. Similar results have been observed in flies containing the Antp open reading frame under heat shock control (Schneuwly et al. 1987a). In this case, though Antp RNAs were expressed in all cells, only the antennae and, to a lesser extent, the head exhibited transformations. 


\section{Discussion}

Abbott and Kaufman (1986) dissected the Antp locus genetically and found that separable functions are associated with particular regions of the gene. They identified two functions for Antp in adult development: A leg disc function is contained within the $3^{\prime}$ portion of the gene, and a wing disc function requires the entire locus intact. Similarly, they subdivided the locus based on the lethal period of various mutants: Antp null mutants die as late embryos; mutants with only the 3 ' portion of the locus $\left(A n t p^{W}\right)$ survive through larval development but die as prepupae; only flies with an intact locus, including the $5^{\prime}$ end, survive to adulthood. A goal of the molecular analyses of the Antp locus is to assign transcripts to the defined genetic functions. Based on $\mathrm{Ab}$ bott's and Kaufman's discussion of the genetic behavior of Antp, three predictions can be made about the molecular characteristics of the locus: (1) Two transcription units exist. The first unit begins in the $5^{\prime}$ half of the locus and continues into the $3^{\prime}$ half, whereas the second unit begins $3^{\prime}$ to the $A n t p^{W}$ inversion breakpoint (Fig. 1). (2) Transcription from the 3' unit should be undisturbed in $A n t p^{\mathrm{w}}$ animals because mutations with similar breakpoints complement both embryonic lethality and leg defects. (3) Wild-type animals will express Antp RNAs in those tissues disrupted by recessive Antp mutations, and dominant mutants will express Antp in those tissues disrupted by dominant Antp mutations. How do the results from the molecular experiments compare with these predictions?

\section{Two transcription units are directed by independent promoters}

Molecular studies of wild-type Antp genes have located transcription start sites both $5^{\prime}$ and $3^{\prime}$ of the Antp ${ }^{w}$ breakpoint (Laughon et al. 1986; Schneuwly et al. 1986; Stroeher et al. 1986). Thus, as predicted, there are two Antp transcription units, one regulated by $\mathrm{Pl}$ and the other by $\mathrm{P} 2$.

Work described here confirms the second prediction. P2 does initiate transcription normally in Antp ${ }^{W}$ animals, indicating that $\mathrm{P} 2$ acts independently of $\mathrm{P} 1$ sequences. Abbott and Kaufman could not predict whether P1 would still be active in $A n t p^{W}$ larvae because the inversion destroys the biological function of these transcripts. RNase protection analysis of $A n t p^{W}$ RNA demonstrated that even though it does not produce transcripts of normal size, P1 still begins transcription at the normal initiation site. Because P1 initiates properly in the absence of P2, P1 is clearly an independent promoter as well.

\section{Transcript location and genetic function}

The most striking result of the in situ hybridization data is that P1 and P2 transcripts are located in different cells of the mesothoracic imaginal discs. Thus, the promoters not only possess independent elements for transcription initiation but also possess different regulatory elements that define the spatial pattern of gene expression.
Moreover, the in situ data concur with the genetic analysis: Transcripts are found in the cells that are defective in mutants. The genetic analyses predict that $\mathrm{Pl}$ RNAs are responsible for identity functions in the prescutum and mesopleura but not in the wing blade of the adult thorax. P1 transcripts were found accordingly in the presumptive prescutum and mesopleura but not in the wing pouch of the wing imaginal disc. The genetic analyses also predict that the $\mathrm{P} 2$ transcripts are responsible for leg development. Consistent with this prediction, P2 transcripts were found in all leg imaginal discs.

However, transcripts from either promoter were also found in cells where no function has been observed. For example, because P1 mutants have normal legs, we do not expect P1 transcripts in wild-type leg discs. Yet, P1 transcripts do accumulate here. Such transcription may be redundant. For example, P1 transcripts may be unnecessary in the legs because P2 RNAs, which encode the same gene product, are also made in these cells. Alternatively, functions for Antp may have been missed in the genetic analysis. We have shown that the wing-associated adepithelial cells contain P2 transcripts. But as these cells will contribute to thoracic musculature and not to cuticle structures, they were not scored in the genetic analysis. Thus, the in situ data suggest that certain tissues could be subjected to further genetic analyses to search for other possible functions of the Antp gene.

To begin to define the DNA elements essential for proper spatial activation, we analyzed transcript distributions in $A n t p^{W}$ larvae. Because the distributions of P1 and P2 mRNAs are maintained in $A n t p^{W}$ homozygotes, each fragment of the locus possesses all of the elements necessary for proper activation, and the cis-relationship between these promoters is not essential. A striking exception to the wild-type distribution was observed in $A n t p^{w}$ larvae: P2 transcripts are found in $A n t p^{W}$ eyeantennal discs, and we believe that they are responsible for the antenna-to-leg transformation seen in this mutant.

\section{Activation of Antp in dominant mutants}

In dominant mutants the Antp gene is misregulated by coupling the open reading frame to a foreign promoter or by activating the endogenous promoter with foreign DNA. In $A n t p^{73 b}$, a foreign promoter is juxtaposed to Antp by an inversion. Fusion RNAs are produced because transcripts are initiated in the foreign gene and then spliced to Antp exons (Frischer et al. 1986; Schneuwly et al. 1987b). The novel transcripts in Antp ${ }^{C B}$ are probably produced by a similar mechanism.

The unique P2 duplication of $A n t p^{N s}$ presents a special case (Fig. 1). Altered P2 regulation may be caused by the repetitive element inserted upstream of the second P2 copy. Examples of such inappropriate gene activation have been observed for the other transposon insertions (Williamson et al. 1983) and proviruses (Dickson et al. 1984; Nusse et al. 1984). Alternatively, the duplication of the sequences including the promoter may itself be responsible for the deregulation of Antp in the head. Such a model has been hypothesized for c-myc activa- 
tion in a Burkitt lymphoma in which the promoters are tandemly duplicated (Taub et al. 1984).

Most often, Antp is misregulated because foreign sequences activate $\mathrm{P} 2$ in the wrong tissue, as observed in $A n t p^{W}, A n t p^{R M}, A n t p^{P W}$, and $A n t p^{C t x}$. In fact, the inversions in the fusion genes $A n t p^{73 b}$ and $A n t p^{C B}$ also activate the remaining Antp promoter, as P2 transcripts were observed in the eye-antennal discs of these mutants. One can argue that in $A n t p^{73 b}$ and $A n t p^{C B}, \mathrm{P} 2$ is not affected directly by the adjacent DNA, but is instead activated by the passing transcription complex initiated at the foreign promoter. However, as concluded from their different transcript distributions in wild-type animals, P2 is not normally activated by upstream P1 transcription. Thus, P2 is misregulated by the inversions associated with all of these dominant mutations. At least two models can explain this activation. P2 could be deregulated by the removal of an upstream repressor element essential for the repression of transcription in the eye-antennal disc. Abbott and Kaufman (1986) have argued persuasively against this model. They have isolated several Antp mutations with inversion or deletion breakpoints interspersed among the breakpoints leading to dominant phenotypes. These mutations should also delete the presumptive repressor element and thus deregulate Antp. Contrary to this prediction, dominant transformations are not associated with this class of rearrangements, and it is therefore unlikely that the deletion of a repressor element is solely responsible for the observed deregulation. Alternatively, the juxtaposed DNA may be asserting a cis-dominant effect on P2 by a tissue-specific enhancer or a chromatin disruption. Euchromatic position effects are commonly observed when transformation places genes in new chromosome locations (Levis et al. 1985; Daniels et al. 1986). Antp misregulation is also analogous to the activation of proto-oncogenes by immunoglobulin gene translocations (reviewed by Cory 1986), in which the activated gene is now under the tissue-specific control of the juxtaposed DNA. Such a model requires that the new DNA adjacent to Antp acts over very large distances: P2 is activated by inversions with breakpoints between $15 \mathrm{~kb}$ $\left(A n t p^{P W}\right)$ and $64 \mathrm{~kb}\left(A n t p^{C B}\right)$ away. Enhancers have been demonstrated to act over $17.5 \mathrm{~kb}$ (Wang and Calame 1985), and translocations greater than $50 \mathrm{~kb}$ away may be capable of promoter activation (Fahrlander et al. 1985; Cleary et al. 1986). Testing this model will require isolating revertants of the dominant phenotype. Revertants that are associated with alterations of the foreign sequences alone would demonstrate that the foreign DNA is responsible for the dominant phenotype. If this model is true, the Antp dominant mutations represent exceptionally long-range euchromatic position effects and provide a model for the role of chromatin structure in the regulation and misregulation of gene expression.

\section{Materials and methods}

Probes

${ }^{32} \mathrm{P}$-Labeled RNA probes were made by in vitro SP6 or T7 transcription, using the conditions described in Stroeher et al.
(1986). ${ }^{35}$ S-labeled RNAs were transcribed under identical conditions, except that the limiting nucleotide was $24 \mu \mathrm{M}$ $\left[\alpha^{-35}\right]$ UTP at $1300 \mathrm{Ci} / \mathrm{mmole}$. These conditions yielded RNAs at specific activities of $2 \times 10^{9}-3 \times 10^{9} \mathrm{dpm} / \mu \mathrm{g}$. ${ }^{35} \mathrm{~S}$-Labeled probes received additional treatments. The DNA template was removed by adding DNase I (Cooper Biochemicals, DPRF) to 1.0 $\mathrm{U} / \mu \mathrm{g}$ DNA template and incubating $30 \mathrm{~min}$ at $37^{\circ} \mathrm{C}$. They were then extracted once with a mixture of phenol, chloroform, and isoamyl alcohol ( $24: 24: 1$ by volume) and once with chloroform. After ethanol precipitation, ${ }^{35} \mathrm{~S}$-labeled probes were hydrolyzed for $90 \mathrm{~min}$ at $60^{\circ} \mathrm{C}$ in a solution of $40 \mathrm{~mm} \mathrm{NaHCO}, 60$ $\mathrm{mM} \mathrm{Na}_{2} \mathrm{CO}_{3}$ (Cox et al. 1984), and ethanol precipitated.

\section{RNase protection}

Total RNA was prepared (Henikoff 1983) from third instar larvae (100 Antp ${ }^{w}$ and 80 wild-type larvae) and treated with 0.1 $\mathrm{U} / \mu \mathrm{l}$ DNase I in $50 \mathrm{mM}$ Tris- $\mathrm{HCl}(\mathrm{pH} 7.5)$ and $10 \mathrm{~mm} \mathrm{MgCl}_{2}$ for $30 \mathrm{~min}$ at $37^{\circ} \mathrm{C}$. RNase protection was performed as described in Stroeher et al. (1986). ${ }^{32} \mathrm{P}$-Labeled antisense RNA was made from a genomic DNA fragment that includes the exon 1 initiation site (see Schneuwly et al. 1986; nucleotides 953-1449 of region 1), or a genomic DNA fragment that includes the exon 3 initiation site (see Schneuwly et al. 1986; $0-745$ of region 3). Nuclease digests were with $40 \mu \mathrm{g} / \mathrm{ml}$ RNase $A$ and $2 \mu \mathrm{g} / \mathrm{ml}$ RNase $T_{1}$ for $1 \mathrm{hr}$ at $30^{\circ} \mathrm{C}$.

\section{In situ hybridization}

Imaginal discs were hand-dissected and fixed for $15 \mathrm{~min}$ in $4 \%$ paraformaldehyde in phosphate-buffered saline (PBS) at $0^{\circ} \mathrm{C}$ and $15 \mathrm{~min}$ in $4 \%$ paraformaldehyde, $0.1 \%$ Triton X-100, and $0.1 \%$ sodium deoxycholate in PBS at room temperature (Kornberg et al. 1985). PBS is $130 \mathrm{~mm} \mathrm{NaCl}, 7 \mathrm{~mm} \mathrm{Na} \mathrm{HPO}_{4}, 3 \mathrm{~mm}$ $\mathrm{NaH}_{2} \mathrm{PO}_{4}$. Discs were either used immediately for hybridization or stored in $100 \% \mathrm{EtOH}$ at $4^{\circ} \mathrm{C}$ and rehydrated in PBS before use.

Whole discs were hybridized in solution and mounted and autoradiographed, as described by Kornberg et al. (1985), with the following alterations. Discs were preincubated for $10 \mathrm{~min}$ in PBSM (PBS with $5 \mathrm{mM} \mathrm{MgCl}$ ) and $10 \mathrm{~min}$ in $0.2 \mathrm{M}$ Tris- $\mathrm{HCl}$ (pH 7.5), and $0.1 \mathrm{M}$ glycine at room temperature (Lawrence and Singer 1985). Hybridizations were in $50 \%$ formamide, $0.6 \mathrm{M}$ $\mathrm{NaCl}, 10 \mathrm{~mm}$ Tris- $\mathrm{HCl}$ (pH 7.5), $1 \mathrm{~mm} \mathrm{Na} \mathrm{N}_{2}$ EDTA, $10 \mathrm{~mm}$ dithiothreitol (DTT), 10\% polyethylene glycol 6000, 1\% SDS, $0.25 \mathrm{mg} / \mathrm{ml}$ Escherichia coli tRNA, and $1 \times$ Denhardt's solution (modified from Hafen et al. 1983; Amasino 1986). ${ }^{35} \mathrm{~S}$-Labeled RNA probes were hybridized at $0.5 \mathrm{ng} / \mu \mathrm{l} \mathrm{kb}$ probe for 20 $\mathrm{hr}$ at $50^{\circ} \mathrm{C}$ and washed twice in PBSM at room temperature for 5 min each. Unhybridized probe was removed by digestion for 1 hr at $37^{\circ} \mathrm{C}$ with $20 \mu \mathrm{g} / \mathrm{ml}$ RNase A in $0.5 \mathrm{M} \mathrm{NaCl}, 10 \mathrm{~mm}$ Tris (pH 8.0), and $10 \mathrm{~mm}$ DTT and incubated for 30 min longer in buffer without enzyme (Cox et al. 1984). Washes continued for 30 -min periods in $2 \times \mathrm{SSC}, 50 \%$ formamide, and $10 \mathrm{~mm}$ DTT and in $1 \times$ SSC, $50 \%$ formamide, and $10 \mathrm{~mm} \mathrm{DTT}$ (both at $50^{\circ} \mathrm{C}$ ) and, finally, in $1 \times$ SSC, $10 \mathrm{~mm} \mathrm{DTT}$, and $0.05 \%$ Triton X-100 at $37^{\circ} \mathrm{C}$ (modified from Lawrence and Singer 1985); $1 \times$ SSC is $0.15 \mathrm{M} \mathrm{NaCl}$ and $0.015 \mathrm{M}$ sodium citrate $(\mathrm{pH} 7.0)$. Discs were placed onto slides, ethanol dehydrated, dipped in undiluted Kodak NTB2 emulsion, and dried horizontally overnight with Drierite. Exposures were approximately 5 days at $4^{\circ} \mathrm{C}$ for wildtype discs; $A n t p^{W} / A n t p^{W}$ and $A n t p^{73 b} /+$ discs were hybridized with the 2.9-kb cDNA 909a and exposed for 19 days and $46 \mathrm{hr}$, respectively; $A n t p^{N s} / A n t p^{N s}$ and $A n t p^{C t x} /+$ discs were hybridized with an exon 3 probe and exposed for 7 and 8 days, respectively. Slides were developed for $2 \mathrm{~min}$ in Kodak D-19 developer 
at $15^{\circ} \mathrm{C}$ and counterstained with $0.5 \%$ Giemsa in $10 \mathrm{~mm}$ $\mathrm{KH}_{2} \mathrm{PO}_{4}$ (pH 7.0). Some investigators (Kornberg et al. 1985) report nonspecific hybridization of ${ }^{35} \mathrm{~S}$-labeled probes to tracheae. We hybridized both Antp sense and a Deformed gene antisense control probes to wing discs and observed only background levels of hybridization to tracheal cells.

For tissue to be sectioned, an equal volume of $95 \%$ ethanol was added dropwise to the final wash solution following whole tissue in situ hybridization, and discs were stored in $100 \%$ ethanol at $4^{\circ} \mathrm{C}$ overnight. The tissue was embedded in $9: 1$ butylmethacrylate : methylmethacrylate and sectioned (Jamrich et al. 1984). Two-micrometer sections were cut on a Sorvall JB-4 microtome, floated onto gelatinized slides, and baked at $60^{\circ} \mathrm{C}$ for $3 \mathrm{hr}$. Plastic was removed by soaking slides for $5 \mathrm{~min}$ each, $3 \times$ in xylene, and $2 \times$ in $100 \%$ ethanol, and then air dried. Slides were dipped once in NTB2 diluted $1: 1$ with water and dried vertically overnight. Exposures were between 10 and 20 days at $4^{\circ} \mathrm{C}$. Developed slides were counterstained as described above.

\section{RNA blot analysis}

Larval tissues were hand-dissected to give roughly equivalent hybridization signals for Antp RNA in wild-type animals. For exon 1 and exon 3 hybridizations, dissected tissues included 107 eye-antennal discs, 111 brain lobes, 32 ventral nerve cords, 108 prothoracic leg discs, 139 mesothoracic leg discs, $131 \mathrm{me}-$ tathoracic leg discs, and 56 wing discs. For exon 8 hybridization, dissected tissues were 143 eye-antennal discs, 134 brain lobes, 66 ventral nerve cords, 115 prothoracic leg discs, $53 \mathrm{me}$ sothoracic leg discs, 54 metathoracic leg discs, and 121 wing discs. Total RNA was fractionated by formaldehyde gel electrophoresis, blotted, and probed according to Stroeher et al. (1986). RNA was bonded to nylon filters by baking blots for $2 \mathrm{hr}$ at $80^{\circ} \mathrm{C}$ and the UV-irradiating with $7000 \mathrm{ergs} / \mathrm{mm}^{2}$ (Church and Gilbert 1984). The exon 1 probe consisted of a DNA fragment taken from the cDNA 958 (see Stroeher et al. 1986; 13-804 in exon 1). The exon 3 probe consisted of two fragments: a $0.61-\mathrm{kb}$ EcoRI-ClaI fragment subcloned from the cDNA 909 (Garber et al. 1983) and a 1.3-kb HindIII-EcoRI genomic fragment that includes the $5^{\prime}$ portion of the exon. The exon 8 probe was a genomic DNA fragment (see Stroeher et al. 1986; exons 4-8, 1495-2042) that did not include the homeo box.

\section{Acknowledgments}

We thank Chris Gaiser and Virginia Stroeher for experimental aid and guidance, and Paul Talbert and Lauren Frischer for sharing unpublished results. We are indebted to Michael $\mathrm{Ab}$ bott for this thoughts on Antp function and for communicating unpublished results. Thomas Kaufman and Michael Abbott kindly provided the fly stocks $A n t p^{w}, A n t p^{R M}$, and $A n t p^{C B}$. We also thank Paul Mahoney, Thomas Kornberg, and Joseph Gall for in situ hybridization protocols, and Barbara Wakimoto, Gerold Schubiger, Gary Karpen, Steve Henikoff, and Bruce Edgar for critical reading of the manuscript. This work was supported by National Institutes of Health $(\mathrm{NIH})$ grant GM33219; E.M.J. was supported by an NIH training grant.

\section{References}

Abbott, M.K. and T.C. Kaufman. 1986. The relationship between the functional complexity and the molecular organization of the Antennapedia locus of Drosophila melanogaster. Genetics 114: 919-942.
Amasino, R.M. 1986. Acceleration of nucleic acid hybridization rate by polyethylene glycol. Anal. Biochem. 152: 304-307.

Benyajati, C., N. Spoerel, H. Haymerle, and M. Ashburner. 1983. The messenger RNA for alcohol dehydrogenase in Drosophila melanogaster differs in its $5^{\prime}$ end in different developmental stages. Cell 33: 125-133.

Brower, D.L., P.A. Lawrence, and M. Wilcox. 1981. Clonal analysis of the undifferentiated wing disk of Drosophila. Dev. Biol. 86: 448-455.

Bryant, P.J. 1975. Pattern formation in the imaginal wing disc of Drosophila melanogaster: Fate map, regeneration, and duplication. J. Exp. Zool. 179: 51-72.

Carlson, M., and D. Botstein. 1982. Two differentially regulated mRNAs with different 5 ' ends encode secreted and intracellular forms of yeast invertase. Cell 28: 145-154.

Church, G.M. and W. Gilbert. 1984. Genomic sequencing. Proc. Natl. Acad. Sci. 81: 1991-1995.

Cleary, M.L., S.D. Smith, and J. Sklar. 1986. Cloning and structural analysis of cDNAs for $b c l-2$ and a hybrid $b c l-2 / \mathrm{immu}$ noglobulin transcript resulting from the $t(14 ; 18)$ translocation. Cell 47: 19-28.

Cory, S. 1986. Activation of cellular oncogenes in hemopoietic cells by chromosome translocations. Adv. Cancer Res. 47: 189-234.

Cox, K.H., D.V. DeLeon, L.M. Angerer, and R.C. Angerer. 1984. Detection of mRNAs in sea urchin embryos by in situ hybridization using asymmetric RNA probes. Dev. Biol. 101: 485-502.

Daniels, S.B., M. McCarron, C. Love, S.H. Clark, and A. Chovnick. 1986. The underlying bases of gene expression differences in stable transformants of the rosy locus in Drosophila melanogaster. Genetics 113: 265-285.

Denell, R.E., K.R. Hummels, B.T. Wakimoto, and T.C. Kaufman. 1981. Developmental studies of lethality associated with the Antennapedia gene complex in Drosophila melanogaster. Dev. Biol. 81: 43-50.

Dickson, C., R. Smith, S. Brookes, and G. Peters. 1984. Tumorigenesis by mouse mammary tumor virus: Proviral activation of a cellular gene in the common integration region int-2. Cell 37: 529-536.

Duncan, I. and E.B. Lewis. 1982. Genetic control of body segment differentiation in Drosophila. In Developmental order: Its origin and regulation, pp. 533-554. Alan R. Liss, New York.

Fahrlander, P.D., M. Piechaczyk, and K.B. Marcu. 1985. Chromatin structure of the murine c-myc locus: Implications for the regulation of normal and chromosomally translocated genes. EMBO I. 4: 3195-3202.

Frischer, L.E., F.S. Hagen, and R.L. Garber. 1986. An inversion that disrupts the Antennapedia gene causes abnormal structure and localization of RNAs. Cell 47: 1017-1023.

Garber, R.L., A. Kuroiwa, and W.J. Gehring. 1983. Genomic and cDNA clones of the homeotic locus Antennapedia in Drosophila. EMBO J. 2: 2027-2036.

Hafen, E., M. Levine, R.L. Garber, and W.J. Gehring. 1983. An improved in situ hybridization method for the detection of cellular RNAs in Drosophila tissue sections and its application for localizing transcripts of the homeotic Antennapedia gene complex. EMBO I. 2: 617-623.

Henikoff, S. 1983. Cloning exons for mapping of transcription: Characterization of the Drosophila melanogaster alcohol dehydrogenase gene. Nucleic Acids Res. 11: 4735-4752.

Jamrich, M., K.A. Mahon, E.R. Gavis, and J.G. Gall. 1984. Histone RNA in amphibian oocytes visualized by in situ hybridization to methacrylate-embedded tissue sections. $E M B O$ I. 3: 1939-1943. 
Kornberg, T., I. Siden, P. O'Farrell, and M. Simon. 1985. The engrailed locus of Drosophila: In situ localization of transcripts reveals compartment-specific expression. Cell 40: 45-53.

Laughon, A., A.M. Boulet, J.R. Bermingham, Jr., R.A. Laymon, and M.P. Scott. 1986. The structure of transcripts from the homeotic Antennapedia gene: Two promoters control the major protein-coding region. Mol. Cell. Biol. 6: 4676-4689.

Lawrence, J.B. and R.H. Singer. 1985. Quantitative analysis of in situ hybridization methods for the detection of actin gene expression. Nucleic Acids Res. 13: 1777-1799.

Levine, M., E. Hafen, R.L. Garber, and W.J. Gehring. 1983. Spatial distribution of Antennapedia transcripts during Drosophila development. EMBO J. 2: 2037-2046.

Levis, R., T. Hazelrigg, and G.R. Rubin. 1985. Effects of genomic position on the expression of transduced copies of the white gene of Drosophila. Science 229: 558-561.

Martinez-Arias, A. 1986. The Antennapedia gene is required and expressed in parasegments 4 and 5 of the Drosophila embryo. EMBO I. 5: 135-141.

Milner, M.J., A.J. Bleasby, and S.L. Kelly. 1984. The role of the peripodial membrane of leg and wing imaginal discs of Drosophila melanogaster during evagination and differentiation in vitro. Roux's Arch. Dev. Biol. 193: 180-186.

Morata, G. and P.A. Lawrence. 1978. Anterior and posterior compartments in the head of Drosophila. Nature 274: 473474.

Nusse, R., A. van Ooyen, D. Cox, Y.K.T. Fung, and H.E. Varmus. 1984. Mode of proviral activation of a putative mammary oncogene (int-1) on mouse chromosome 15. Nature 307: 131-136.

Poodry, C.A. 1980. Imaginal discs: Morphology and development. In The genetics and biology of Drosophila (ed. M. Ashburner, T.R.F. Wright), vol. 2d, pp. 407-441. Academic Press, London.

Sato, T., P.H. Hayes, and R.E. Denell. 1985. Homoeosis in Drosophila: Roles and spatial patterns of expression of the $A n$ tennapedia and Sex combs reduced loci in embryogenesis. Dev. Biol. 111: 171-192.

Schibler, U., O. Hagenbuchle, P.K. Wellauer, and A. Pittet. 1983. Two promoters of different strengths control the transcription of the mouse $\alpha$-amylase gene $A m y-1^{A}$ in the parotid gland and the liver. Cell 33: 501-508.

Schneuwly, S. and W.J. Gehring. 1985. Homeotic transformation of thorax into head: Developmental analysis of a new Antennapedia allele in Drosophila melanogaster. Dev. Biol. 108: $377-386$.

Schneuwly, S., R. Klemenz, and W.J. Gehring. 1987a. Redesigning the body plan of Drosophila by ectopic expression of the homoeotic gene Antennapedia. Nature 325: 816-818.

Schneuwly, S., A. Kuroiwa, P. Baumgartner, and W.J. Gehring. 1986. Structural organization and sequence of the homeotic gene Antennapedia of Drosophila melanogaster. EMBO $J$. 5: 733-739.

Schneuwly, S., A. Kuroiwa, and W.J. Gehring. 1987b. Molecular analysis of the dominant homeotic Antennapedia phenotype. $E M B O$ I. 6: 201-206.

Schubiger, G. 1968. Anlageplan, Determinationszustand, und Transdeterminationsleistungen der mannlichen Vorderbeinscheibe von Drosophila melanogaster. Wilhelm Roux's Arch. 160: 9-40.

Scott, M.P., A.J. Weiner, T.I. Hazelrigg, B.A. Polisky, V. Pirrotta, F. Scalenghe, and T.C. Kaufman. 1983. The molecular organization of the Antennapedia locus of Drosophila. Cell 35: 763-776.

Steiner, E. 1976. Establishment of compartments in the devel- oping leg imaginal discs of Drosophila melanogaster. Wilhelm Roux's Arch. 180: 9-30.

Stroeher, V.L., E.M. Jorgensen, and R.L. Garber. 1986. Multiple transcripts from the Antennapedia gene of Drosophila. Mol. Cell. Biol. 6: 4667-4675.

Struhl, G. 1981. A homeotic mutation transforming leg to antenna in Drosophila. Nature 292: 635-638.

Taub, R., K. Kelly, J. Battey, S. Latt, G.M. Lenoir, U. Tantravahi, $Z$. Tu, and P. Leder. 1984. A novel alteration in the structure of an activated c-myc gene in a variant $t(2 ; 8)$ Burkitt lymphoma. Cell 37: 511-520.

Wakimoto, B.T. and T.C. Kaufman. 1981. Analysis of larval segmentation in lethal genotypes associated with the $A n$ tennapedia gene compex. Dev. Biol. 81: 51-64.

Wang, X. and K. Calame. 1985. The endogenous immunoglobulin heavy chain enhancer can activate tandem $V_{H}$ promoters separated by a large distance. Cell 43: 659-665.

Williamson, V.M., D. Cox, E.T. Young, D.W. Russel, and M. Smith. 1983. Characterization of transposable element-associated mutations that alter yeast alcohol dehydrogenase II expression. Mol. Cell. Biol. 3: 20-31. 


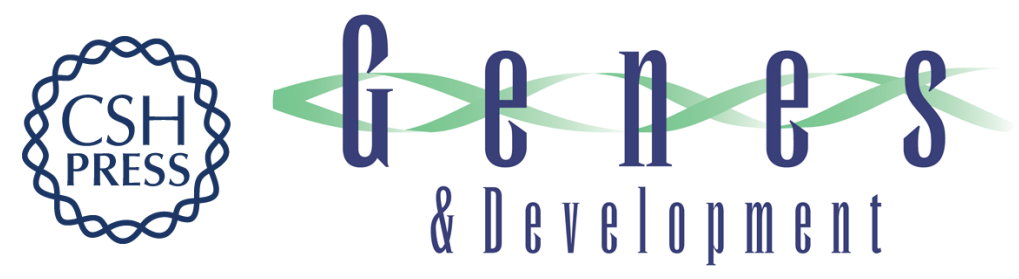

\section{Function and misfunction of the two promoters of the Drosophila Antennapedia gene.}

E M Jorgensen and R L Garber

Genes Dev. 1987, 1:

Access the most recent version at doi:10.1101/gad.1.6.544

References This article cites 43 articles, 7 of which can be accessed free at: http://genesdev.cshlp.org/content/1/6/544.full.html\#ref-list-1

License

Email Alerting

Receive free email alerts when new articles cite this article - sign up in the box at the top Service right corner of the article or click here.

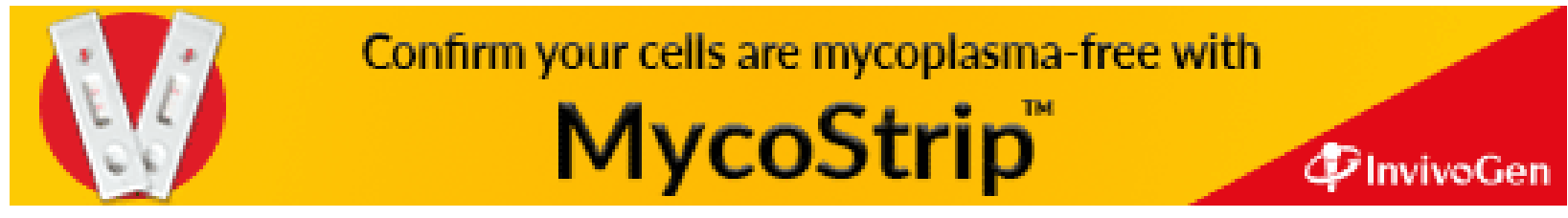

